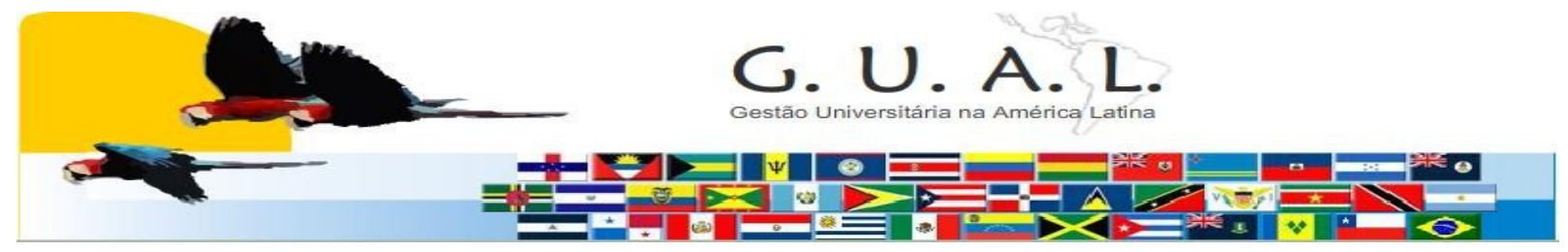

ISSN 1983-4535

\title{
ESTRUTURAÇÃO DE UM MODELO DE CUSTEIO HÍBRIDO PARA UMA FUNDAÇÃO DE APOIO UNIVERSITÁRIA
}

\author{
Fernando Richartz, Mestre \\ Universidade Federal de Santa Catarina - UFSC \\ nandorichartz@hotmail.com
}

Altair Borgert, Doutor

Universidade Federal de Santa Catarina - UFSC

borgert@cse.ufsc.br

Ráriton Silva, Bacharel Fundação de Amparo a Pesquisa e Extensão Universitária da UFSC - FAPEU

rariton@fapeu.org.br

\section{RESUMO}

O objetivo deste estudo é estruturar um modelo de custeio híbrido (ABC e UEP) para quantificação dos gastos necessários ao gerenciamento dos projetos de pesquisa de uma fundação de apoio universitária. Como objeto de estudo, utiliza-se o convênio Pequim Internacional 2, desenvolvido pela Fundação de Amparo a Pesquisa e Extensão Universitária. Os dados necessários para a estruturação do modelo foram coletados por meio de verificação in loco e junto às gerências da fundação, em especial, com a gerência financeira, durante o segundo semestre de 2010. O modelo foi estruturado em oito etapas, desenvolvido com base na literatura disponível sobre o assunto. Sua aplicação evidenciou um custo de R $\$ 13.330,55$ para o projeto em questão. Assim, no mínimo este valor deve ser ressarcido para a fundação a título de despesas administrativas. Em relação ao total do objeto conveniado ( $\mathrm{R} \$ 250.000,00)$, de acordo com os resultados obtidos com a aplicação do modelo, os gastos da fundação encontram-se dentro do limite de quinze por cento $(\mathrm{R} \$ 37.500,00)$ estipulados pela Portaria Interministerial $\mathrm{n}^{\mathrm{o}} 127$ de 29 de maio de 2008. Cabe ressaltar que, além do custeamento de convênios, esta metodologia se apresenta viável como instrumento de gestão para as fundações, tendo em vista que permite o mapeamento das atividades desenvolvidas e sua mensuração e controle, o que potencializa o gerenciamento dos pontos deficitários da organização.

Palavras-chave: Modelo de custeio híbrido. ABC. UEP. Fundação de apoio. 


\section{INTRODUÇÃO}

No que diz respeito às fundações, Silveira (2007, p.45) diz que "a classificação das fundações ainda não é um tema pacífico entre os autores, devido à própria diversidade de perspectivas que podem ser dadas aos tipos identificáveis”. Paes (2006) sugere cinco tipos distintos de fundações, são eles: a) fundação instituída por pessoa física ou jurídica; b) fundação instituída por empresas; c) fundação instituída por partido político; d) fundação de apoio às instituições de ensino superior; e) fundação de previdência privada ou complementar. Neste artigo, o objeto de estudo é uma fundação de apoio às instituições de ensino superior.

De acordo com o Ministério da Educação (2010), as fundações de apoio são instituições criadas com a finalidade de apoiar projetos de pesquisa, ensino, extensão e de desenvolvimento institucional, científico e tecnológico, de interesse das instituições federais de ensino superior (IFES) e também das instituições de pesquisa. Devem ser constituídas na forma de fundações de direito privado sem fins lucrativos e serão regidas pelo Código Civil.

Segundo a Fundação de Empreendimentos Científicos e Tecnológicos (2010), as instituições federais brasileiras sofrem de um grande mal: a burocracia. Desta forma, para que os efeitos burocráticos sejam minimizados são instituídas as fundações de apoio. Por meio destas fundações, os investidores externos à instituição, conseguem investir recursos diretamente na instituição federal que eles desejam. Caso contrário, sem o papel das fundações de apoio, os recursos são depositados em uma conta única do tesouro nacional e o seu destino é incerto.

Assim, visando facilitar a aplicação de recursos nas instituições de ensino superior, estas instituições criam as fundações de apoio com a finalidade de viabilizar as ações administrativas e captar recursos que possibilitam o desenvolvimento do ensino e da pesquisa universitária. A gestão das fundações é disciplinada por normas e resoluções dos conselhos superiores das IFES e fiscalizadas externamente pelos órgãos de financiamento, pelas secretarias de controle interno dos ministérios, pelos tribunais de contas do estado e da união e pelo Ministério Público. (BRASIL, LEI Nº 8.958, 1994)

As fundações de apoio não são criadas por lei nem mantidas pela União. Desta forma, apesar de criar as fundações, as IFES não oferecem suporte financeiro para as mesmas. Neste caso, suas receitas são oriundas de atividades próprias, destacando-se as verbas provenientes da elaboração e execução de contratos e as rendas auferidas por serviços prestados por 
intermédio de projetos.

Contudo, na celebração de convênios para os projetos de pesquisa financiados por órgãos públicos, disciplinados pela Instrução Normativa STN nº 01 de 15 de janeiro de 1997, as fundações são impossibilitadas de receber qualquer remuneração a título de taxa de administração. Para agravar a situação, tais convênios são complexos e exigem das fundações uma estrutura ágil e eficiente para atender todas as necessidades e as exigências legais implícitas na celebração destes convênios.

Por outro lado, por meio da Portaria Interministerial no 127 de 29 de maio de 2008, existe a possibilidade de que os gastos da entidade privada, atribuídos como despesas administrativas, possam ser ressarcidos, desde que: a) estejam previstos e detalhados no plano de trabalho aprovado pela concedente; b) não excedam quinze por cento do valor objeto do convênio; c) não tenham sido custeados com recursos originários de outras fontes.

Assim, para haver ressarcimento das despesas, as fundações necessitam de um sistema de controle de custos que proporciona tais informações. Assim, ao perceber a complexidade de gerenciamento das atividades das fundações, concorda-se com Vanderbeck e Nagy (2003 p. 14), os quais afirmam que "todos os tipos de entidades comerciais, empresas de manufatura, de comércio e de serviços necessitam de sistemas de informação de contabilidade de custos para contabilizarem as suas atividades". Neste caso, os sistemas de custeio são considerados como ferramentas necessárias ao fornecimento destas informações.

Os fatores apresentados, aliados à ausência de controle de custos por parte das fundações, levam a necessidade de desenvolver um sistema de custeio para as Fundações. Contudo, "para que um Sistema de Custeio atenda às necessidades de geração de informações nas organizações, faz-se necessária a utilização de um Método de Custeio ou a combinação de mais de um deles". (SILVA; BORGERT; SCHULTZ, 2009, p.218)

Portanto, o objetivo deste trabalho é estruturar um modelo de custeio híbrido baseado na união dos conceitos do Custeio Baseado em Atividades (ABC) e do Método das Unidades de Esforço de Produção (UEP) - que possibilite quantificar os gastos necessários para a realização dos projetos de pesquisa das fundações de apoio. Para atingir este objetivo e criar um modelo para as fundações, utiliza-se como objeto de estudo o convênio Pequim Internacional 2, desenvolvido pela Fundação de Amparo a Pesquisa e Extensão Universitária.

Assim, este trabalho possui dois fatores motivacionais: 1) Evidenciar, de forma 
detalhada, os recursos consumidos em cada projeto, sendo esta uma das exigências para haver ressarcimento; e ainda, apresentar informações, detalhadas por atividades, que auxiliem na redução dos custos, haja vista que estes não podem ultrapassar quinze por cento do total do convênio; 2) Trazer contribuições para o meio acadêmico nos aspectos que tangem a metodologia de custeio híbrida aplicada à prestação de serviço, em especial, as fundações de apoio, em virtude da necessidade desenvolvimento e aprimoramento de sistemas de gestão que auxiliem estas organizações.

\section{FUNDAÇÕES DE APOIO}

As Fundações são caracterizadas por Paes (2006) como instituições de fins determinados, formadas pela atribuição de personalidade jurídica ao patrimônio, o qual será administrado por órgãos autônomos, em conformidade com as previsões do estatuto. Para Miranda (2004, p.326) “a fundação é uma pessoa jurídica de direito privado, cujos bens foram destinados por seu fundador para a consecução de certos fins. Certamente possuem um criador, um conjunto de bens destinados a um fim específico e finalidade pública".

Conforme Diniz (1998, p.11),

A fundação é um complexo de bens livres (universitas bonorum), colocado,
por uma ou mais pessoas físicas ou jurídicas, sem intuito de lucro, a serviço
de um fim lícito e especial com alcance social, em atenção ao disposto em
seu estatuto. É, portanto, um patrimônio destinado a uma finalidade
socialmente útil, ou seja, filantrópica, que lhe dá unidade.

Silveira (2007) destaca que as fundações são instituídas para finalidades públicas e seu patrimônio é constituído de bens que passam a ser de interesse coletivo, portanto, passível de fiscalização do Estado. Assim, a administração das fundações e a manutenção de suas finalidades são de interesse público.

As fundações não são todas iguais. Pelo contrário, existem diversos tipos distintos destas organizações. No entanto, neste trabalho, aborda-se apenas as fundações de apoio, visto que a estruturação do sistema de custeio em questão destina-se, principalmente, a fundações desta natureza. As fundações de apoio às instituições de ensino superior visam auxiliar as atividades das instituições de ensino superior ao qual estão vinculadas.

As fundações de apoio possuem natureza jurídica, e são reguladas pelo Código Civil e

Rev. GUAL., Florianópolis, v. 4, n. 3, p.21-43, set/dez. 2011 
pelo código processual civil e são constituídas mediante aprovação de seu estatuto pelo Ministério Público. Desta maneira, uma Fundação de apoio reflete a posição das fundações de direito privado que foram instituídas por pessoas físicas ou pessoas jurídicas, visando a auxiliar e fomentar os projetos de pesquisa, ensino e extensão das universidades federais e das demais instituições de ensino superior, públicas ou privadas. (PAES, 2006).

Segundo Pasquatti (2003) as fundações de apoio são entidades de direto privado, sem fins lucrativos, e instituídas com fulcro no Código Civil. Elas não são vinculadas ao poder público, muito menos fazem parte da administração pública. Como o próprio nome sugere, as fundações de apoio dão suporte à diversas atividades realizadas pelas IES.

Para poder atender aos objetivos dos convênios, as fundações devem possuir padrões mínimos de qualificação técnica e de capacidade operacional que deverão ser confirmados pela concedente por meio de análise de desempenho anteriores, na realização de objetos semelhantes, para verificar a existência de uma infra-estrutura mínima necessária à realização das atividades, na verificação de um corpo técnico qualificado, e que a instituição possua similaridade entre o objeto do convênio e o seu ramo de atuação.

Para o atendimento de todas estas exigências, inclusive a própria celebração do convênio, as fundações decorrem de uma série de despesas administrativas. No entanto, como é impossibilitada a cobrança da taxa de administração, estas despesas deverão ser custeadas com receitas próprias, configurando-se como um ônus na realização dos convênios.

Conforme já mencionado, a Instrução Normativa STN n.01 de 15 de janeiro de 1997 que "disciplina a celebração de convênios de natureza financeira que tenham por objeto a execução de projetos ou realização de eventos", dispõe no seu art.8:

Art 8. É vedada a inclusão, tolerância ou admissão, nos convênios, sob a pena de nulidade do ato e responsabilidade do agente, de cláusula ou condições que prevejam ou permitem: I - realização de despesas a título de taxa de administração, de gerência ou similar.

Desta maneira, por haver a impossibilidade da cobrança da taxa de administração, a alternativa dada às fundações é o ressarcimento das despesas administrativas, desde que obedecidos os critérios da Portaria Interministerial $n^{\circ} 127$ de 29 de maio de 2008. Com esta possibilidade, uma das exigências é para as fundações é desenvolver uma ferramenta que possibilite a identificação destas despesas da forma mais correta possível, sem correr o risco de apresentar valores arbitrários. Esta ferramenta, depois de elaborada, apresenta duas 
funções principais: a) Identificar o montante gasto com despesas administrativas na celebração dos convênios; b) Desempenhar a função gerencial de melhoramento da eficiência dos processos, tendo em vista que as despesas administrativas, para serem ressarcidas, não podem exceder quinze por cento do valor do objeto conveniado.

\section{SISTEMAS DE GESTÃO DE CUSTOS}

Um sistema de gestão de custos pode ser definido como a combinação de órgãos, critérios, fluxos de dados, informações, conceitos e definições relacionadas aos custos que se destinam a servir de base para os diversos níveis gerenciais. (LEONE, 2000). Desta maneira, Bornia (2002) afirma que este sistema de custos deve estar em sintonia com o sistema de gestão da empresa, relacionando-se com a estratégia gerencial, identificando que tipo de informação se deseja obter e qual a finalidade desta informação.

O sistema de custos pode ser analisado sob duas óticas: a) as informações se adéquam as necessidades da empresa, desta forma o sistema fornece apenas informações relevantes; $b$ ) o segundo ponto de vista leva em consideração a operacionalização do sistema para o fornecimento destas informações. Assim, os métodos de custeio são as ferramentas utilizadas para obter informações vistas sob o prisma da operacionalização. (BORNIA, 2002).

A partir deste pressuposto, para operacionalizar um sistema de gestão de custos faz-se necessário o uso de um método de custeio ou a integração diversos métodos. Dentre os métodos disponíveis, aplica-se neste trabalho o ABC conjuntamente com o método UEP que resulta no método de custeio híbrido.

\subsection{Custeio baseado em atividades (ABC)}

$\mathrm{O}$ método de custeio baseado em atividades $(\mathrm{ABC})$ tem sua nomenclatura originária do termo em inglês Activity Based Costing. Hansen e Mowen (2001, p. 392) afirmam que o sistema $\mathrm{ABC}$ "primeiramente rastreia os custos para as atividades e, em seguida, para os produtos e outros objetos de custos". Para Bornia (2002, p. 122), “o custeio baseado em atividades pressupõe que as atividades consomem recursos, gerando custos, e que os produtos utilizam tais atividades, absorvendo seus custos".

Para entender esta sistemática, é necessário esclarecer primeiramente o que é uma atividade. Segundo Martins (2006, p. 93), “atividade é uma ação que utiliza recursos 
humanos, materiais, tecnológicos e financeiros para se produzir bens ou serviços”. Assim, para que um processo seja concluído é necessário que diversas atividades sejam executadas.

No processo de implementação do $\mathrm{ABC}$, depois de identificadas as atividades principais, atribuem-se os custos a estas atividades. Nesse sentido, Martins (2006) afirma que, para alocar os recursos às atividades, utilizam-se os direcionadores de custos de recursos, os quais têm a finalidade de identificar a maneira como as atividades consomem recursos no processo de custear as atividades, demonstrando a relação entre os recursos e as atividades.

Após custeadas as atividades, o próximo passo é distribuir os custos aos produtos. Para esta distribuição, Martins (2006) orienta que se faça a alocação utilizando direcionadores de custos de atividades, os quais identificam como os produtos consomem as atividades, ou seja, indica a relação entre as atividades e os produtos.

Em suma, o custeio baseado em atividades, busca identificar, classificar e mensurar como as atividades consomem os recursos e posteriormente identificar como os produtos consomem as atividades de uma empresa, sempre com o intuito de analisar e monitorar as diversas rotas de consumo dos recursos com as atividades mais relevantes, e destas para os produtos e serviços. (NAKAGAWA, 2001). Com isso tenta-se reduzir a subjetividade na alocação dos custos indiretos, o que permiti mensurar o que se agrega de valor aos serviços, e focar na gestão das atividades necessárias para a execução das finalidades da empresa.

\subsection{Unidades de esforço de produção (UEP)}

O método das Unidades de Esforço de Produção teve seu advento no final da Segunda Guerra Mundial, fruto do trabalho do engenheiro francês Georges Perrin, e foi trazido ao Brasil na década de 1960 pelo engenheiro Franz Allora.

De acordo com um estudo realizado por Kraemer (1995), este método foi aprimorado no Brasil por uma equipe de pesquisadores - alunos de mestrado - da Universidade Federal de Santa Catarina (UFSC), no ano de 1988. Na UFSC resgatou-se sua real abrangência, por servir como instrumento gerencial não só para a compreensão dos custos industriais, mas também, da produtividade, no que se refere ao controle e à avaliação do nível de eficiência, eficácia e ociosidade do chão-de-fábrica.

Segundo Martins e Barrela (2002), o método da UEP se baseia na unificação da produção que, inicialmente, objetivava solucionar o problema do custeio da produção e evitar 
o rateio das despesas gerais para os diversos produtos. Sua proposta é transformar uma empresa multiprodutora real em uma empresa monoprodutora fictícia, e com isso, obter as facilidades de mensuração de uma empresa monoprodutora.

Kliemann Neto (1995) acredita ser fundamental, para conseguir transformar uma empresa em monoprodutora, a noção de esforço de produção, ou seja, quaisquer que sejam os artigos fabricados necessita-se de esforços de produção de mesma natureza, embora de diferentes intensidades. Neste caso, produtos até então sem nenhuma relação, tornam-se comparáveis. Ou seja, a UEP representa o trabalho realizado para a transformação das matérias-primas em produtos acabados.

Ainda na visão de Kliemann Neto (1995), são cinco as etapas para implementação do método das UEPs: 1) definição dos roteiros de produção dos diversos produtos; 2) definição de um produto-base; 3) cálculo do foto-custo do produto-base; 4) cálculo dos potenciais produtivos dos postos operativos; e 5) cálculo do valor dos produtos em UEPs.

Desta maneira, conclui-se que o método das unidades de esforço de produção tem a finalidade de agilizar o controle e o gerenciamento do processo produtivo, sem que seja perdida a confiabilidade das informações geradas por ele.

\subsection{Modelo de custeio híbrido (ABC e UEP)}

Para equacionar os problemas e vantagens inerentes a implantação e manutenção que cada sistema proporciona, procura-se a adoção da utilização conjunta dos métodos $\mathrm{ABC}$ e UEP para unificar a eficiência do $\mathrm{ABC}$ como uma importante ferramenta de controle e tomada de decisão, com a simplicidade de operacionalização oferecida pelo UEP.

Assim, fazendo-se do uso dos conceitos sobre ABC e UEP disponíveis na literatura, Borgert; Borba e Silva (2005), Machado; Borgert e Lunkes (2006), Silva (2006) e Silva, Borgert e Schultz (2009) estruturaram um modelo de custeio denominado "custeio híbrido" que consiste na união dos conceitos do ABC e do UEP. Para este estudo houve uma adaptação deste modelo, o que resultou em oito principais etapas de execução:

1. Mapear os serviços: conhecer os serviços prestados pela fundação e seus processos de execução;

2. Mapear as atividades: identificar e separar os centros de atividades da fundação;

3. Identificar os custos: nesta etapa são identificados todos os gastos necessários a manutenção das atividades desenvolvidas pela fundação; 
4. Identificar os direcionadores: com base nas informações obtidas na segunda e terceira etapa, identificar direcionadores de custos para a alocação dos valores às atividades;

5. Alocar os custos às atividades: transferir os custos identificados para as atividades geradoras, por meio da utilização dos direcionadores de custos identificados na etapa quatro;

6. Calcular o Custo da Atividade por Hora (CAH): o CAH é obtido por meio da fórmula $-\mathrm{CAH}=\mathrm{CA} \div \mathrm{Np}$, onde: $\mathrm{CA}$ é o custo total da atividade e $\mathrm{Np}$ o tempo padrão (horas efetivas trabalhadas no mês);

7. Definir e calcular o Custo do Serviço Base (CSB): o serviço base deve ser um serviço prestado pela fundação ou a combinação de dois ou mais serviços. O custo do Serviço Base é obtido da seguinte forma: $\mathrm{CSB}=\Sigma(\mathrm{CAH} \times \mathrm{Npa})$, onde: $\mathrm{CAH}$ é o Custo da Atividade por Hora e o Npa o tempo de passagem do serviço padrão na atividade;

8. Cálculo da Constante de Esforço da Atividade (CEA): é obtido pela fórmula CEA $=\mathrm{CAH} \div \mathrm{CSB}$, onde: CEA é a Constante de Esforço da Atividade, CAH é o Custo da Atividade por Hora e CSB o Custo do Serviço-Base.

Como resultado da unificação do $\mathrm{ABC}$ com a UEP, acredita-se que se possa estabelecer um método de custeio que, após a fase de implementação seja capaz de fornecer informações úteis ao processo de gestão e com baixa aplicação de recursos humanos e tecnológicos (SILVA, 2006).

\section{METODOLOGIA}

A presente pesquisa consiste num estudo prático voltado para a estruturação de um modelo de custeio híbrido - que se apóia na união dos conceitos do ABC com UEP - para o custeamento dos convênios e projetos executados pelas fundações de apoio. Utiliza-se a Fundação de Amparo a Pesquisa e Extensão Universitária - FAPEU como base para a estruturação do sistema de custeio híbrido. Dos mais de oitocentos projetos desenvolvidos atualmente pela fundação, escolheu-se o convênio Pequim Internacional 2 como modelo. Selecionou-se este convênio pelo fato de representar adequadamente os processos executados pela FAPEU, servindo assim, de parâmetro para os demais convênios.

O estudo possui finalidade exploratória e descritiva e apresenta características tanto qualitativas quanto quantitativas tendo em vista que a estruturação de um sistema de gestão de custos, além de apresentar dados quantitativos aos gestores exige também interpretações qualitativas em diversas situações, principalmente no rastreamento dos custos para os serviços. Pelo fato do modelo tratar de um caso em específico (desenvolvido na FAPEU), utiliza-se o estudo de caso como meio para atingir os objetivos propostos. 
Os dados necessários para a estruturação do modelo de custeio foram coletados durante o segundo semestre de 2010 e são referentes ao mês de junho deste mesmo ano. As informações primárias foram obtidas junto às gerências da fundação, em especial, com a gerência financeira, e por meio da observação participante. Ainda, para completar algumas informações faltantes, fez-se necessária a consulta ao site da fundação, o que resulta em informações secundárias.

Em relação ao método utilizado, Erhart et al. (2005) perceberam ser pertinente a utilização de mais de um método de custeio, podendo-se explorar as vantagens de cada um deles e a sua associação aos princípios de custeio por absorção parcial e total, respectivamente. Além disso, a definição do sistema de custeio e do seu respectivo nível de agregação deve confrontar os benefícios das informações geradas com os seus custos de implantação e manutenção. Com a implementação do ABC, por exemplo, as empresas começam a compreender-se por processos e questionar a real agregação de valor de suas atividades.

Beuren e Schlindwein (2008), seguindo a lógica da união de métodos, trataram de unir os conceitos do custeio por absorção e do RKW. O objetivo do estudo destes autores foi “demonstrar o uso do custeio por absorção aliado ao sistema RKW para gerar informações gerenciais em uma organização hospitalar, dispensando assim um sistema paralelo de custeio e os custos a ele relacionados para atendimento dos preceitos legais".

Conforme já mencionado, Borgert; Borba e Silva (2005), Machado; Borgert e Lunkes (2006), Silva (2006) e Silva, Borgert e Schultz (2009), tem trabalhado a aplicação da metodologia de custeio híbrida (União dos conceitos do $\mathrm{ABC}$ e da UEP) na prestação de serviços. Estes estudos focaram organizações hospitalares, empresas de softwares e escritórios de advocacia. No entanto, não foram encontrados registros da aplicação desta metodologia em fundações. Assim, esta pesquisa visa fornecer subsídios para a gestão das fundações e ainda contribuir, através do modelo desenvolvido, para futuras pesquisas relacionadas a esta temática.

\section{APRESENTAÇÃO DOS RESULTADOS}

Nesta seção, inicialmente apresenta-se a fundação objeto deste estudo, sua estrutura organizacional, os projetos desenvolvidos e em especial o convênio Pequim Internacional 2. 
Posteriormente se faz a estruturação do modelo de custeio híbrido para a fundação em questão utilizando como exemplo o convênio Pequim Internacional 2.

\subsection{Caracterização da Fundação}

A Fundação de Amparo à Pesquisa e Extensão Universitária - FAPEU, foi instituída pela Universidade Federal de Santa Catarina - UFSC em 1977, com a finalidade de viabilizar as ações administrativas e captar recursos que possibilitam o desenvolvimento do ensino e da pesquisa universitária. A FAPEU é uma instituição privada sem fins lucrativos que tem como missão, "Promover o desenvolvimento científico, tecnológico e social, através do apoio à comunidade universitária da Universidade Federal de Santa Catarina“.

A gestão da fundação é disciplinada por normas e resoluções do conselho superior da UFSC e fiscalizada externamente pelos órgãos de financiamento, pelas secretarias de controle interno dos ministérios, pelos tribunais de contas do estado e da união e pelo Ministério Público. Apesar de ter criado a fundação, a UFSC não oferece suporte financeiro para a FAPEU. Neste caso, suas receitas são oriundas de atividades próprias, com destaque para as verbas provenientes da elaboração e execução de contratos e as rendas auferidas por serviços prestados por intermédio de projetos.

Atualmente, a fundação possui uma estrutura técnica que permite ao coordenador dos projetos acessar os órgãos financiadores e apresentar a proposta para a obtenção dos recursos, bem como a estrutura de compras, de recrutamento e pagamento de pessoal, de assessoria jurídica, de informática, financeira e contábil, de arquivo e prestação de contas. Todas estas atividades seguem religiosamente as orientação e determinações dos órgãos financiadores e da legislação vigente.

Os serviços prestados pela FAPEU são basicamente nas áreas de projetos de pesquisa científica e tecnológica; projetos de $\mathrm{P} \& \mathrm{D}$; projetos com incentivos fiscais; prestação de serviços, consultorias e assessorias técnicas e tecnológicas; cursos de extensão e eventos. $\mathrm{Na}$ Figura 1 observa-se o organograma da FAPEU e fica possível compreender melhor o processo de funcionamento da fundação. 


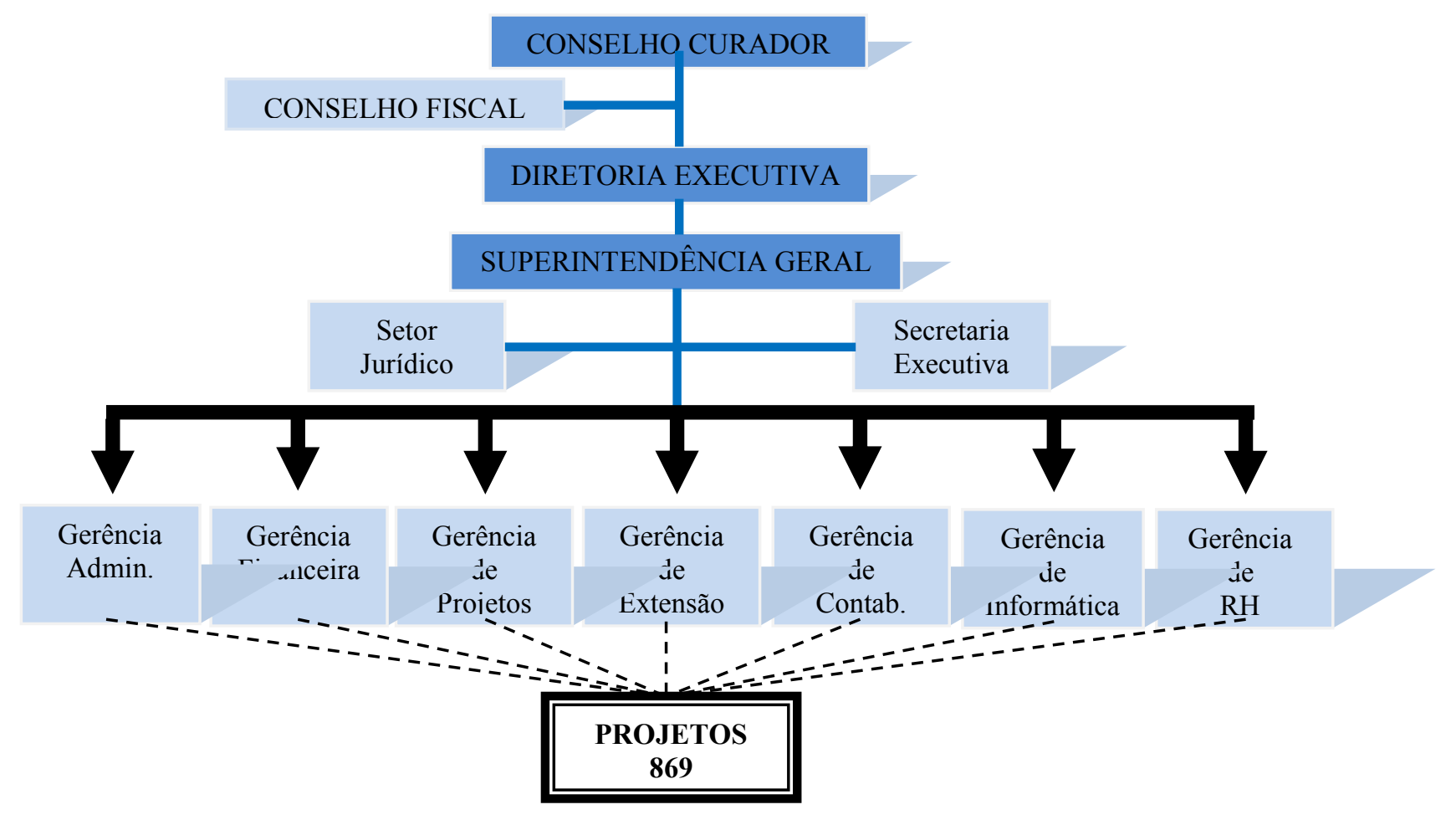

Figura 1 Organograma da FAPEU

Fonte: FAPEU (2011)

Atualmente a FAPEU possui 869 projetos ativos. Para suprir esta quantidade de serviço a fundação conta com o apoio direto das Gerências Administrativa, Financeira, de Projetos, de Extensão, de Contabilidade, de Informática e de Recursos Humanos. Entre estes projetos, está o convênio Pequim Internacional 2 que se refere ao segundo curso regional de proteção e assistência para respostas emergenciais químicas. Este convênio está firmado em R\$ 250.000,00 e é financiado pelo Ministério da Integração Nacional. No entanto, conforme outrora mencionado, gerenciar um convênio resulta em gastos para a fundação, que por sua vez não pode cobrar taxa de administração. No entanto, as despesas podem ser ressarcidas, mas para isso, precisam de um sistema de controle de custos que comprove suas aplicações.

\subsection{Estruturação do modelo de custeio híbrido (ABC e UEP)}

Para a estruturação do modelo de custeio para a fundação, utiliza-se a metodologia híbrida (ABC e UEP). Este modelo consiste em unir uma ferramenta gerencial consolidada, que é o $\mathrm{ABC}$ com a facilidade de operacionalização da UEP. O modelo será desenvolvido 
para a fundação como um todo, no entanto será plicado apenas no convênio Pequim Internacional 2.

Cabe destacar que a metodologia de custeio híbrida terá sua primeira aplicação em fundações de apoio. O modelo está dividido em oito etapas, e trata-se se uma adaptação do modelo original. A primeira etapa - mapear os serviços, já está descrita na seção de caracterização da fundação.

Identificados os serviços prestados pela fundação de apoio, a segunda etapa consiste em mapear as atividades necessárias à consecução destes serviços. O Quadro 1 lista as atividades essenciais ao funcionamento da fundação em estudo e apresenta uma breve descrição do que se trata e qual a finalidade das atividades em questão.

\begin{tabular}{|l|l|l|}
\hline \multicolumn{2}{|c|}{ ATIVIDADE } & \multicolumn{2}{c|}{ DESCRIÇÃO } \\
\hline 01 & $\begin{array}{l}\text { Comprar } \\
\text { internamente }\end{array}$ & $\begin{array}{l}\text { Realiza cotação, fechamento do pedido, cobrança de entrega de materiais } \\
\text { de consumo, equipamentos e produtos de laboratório no mercado nacional }\end{array}$ \\
\hline 02 & Importar & $\begin{array}{l}\text { Realiza cotação, fechamento do pedido, cobrança de entrega de materiais } \\
\text { de consumo, equipamentos e produtos de laboratório no exterior }\end{array}$ \\
\hline 03 & Efetuar reservas & $\begin{array}{l}\text { Realiza cotação, fechamento do pedido, cobrança de entrega e efetivação } \\
\text { de passagens e hospedagens }\end{array}$ \\
\hline 04 & Licitar & $\begin{array}{l}\text { Realiza os procedimentos legais para a realização do edital, abertura e } \\
\text { finalização do processo de licitação. }\end{array}$ \\
\hline 05 & Apoiar CLT & $\begin{array}{l}\text { Realiza os procedimentos de seleção, documentação, contratação e } \\
\text { pagamento de pessoal contratado. }\end{array}$ \\
\hline 06 & Apoiar bolsistas & $\begin{array}{l}\text { Realiza os procedimentos de seleção, documentação, contratação e } \\
\text { pagamento de bolsistas. }\end{array}$ \\
\hline 07 & $\begin{array}{l}\text { Apoiar prestadores } \\
\text { de serviço }\end{array}$ & $\begin{array}{l}\text { Realiza os procedimentos de seleção, documentação, contratação e } \\
\text { pagamento de prestadores de serviço. }\end{array}$ \\
\hline 08 & Gerenciar projetos & $\begin{array}{l}\text { Gerenciar um conjunto de ações e procedimentos visando a gestão de } \\
\text { projetos }\end{array}$ \\
\hline 09 & Firmar contratos & Realiza contratos com a UFSC e projetos de extensão. \\
\hline 10 & Pagar & Realiza pagamentos a pessoas físicas e jurídicas \\
\hline 11 & Receber & Realiza a emissão de faturas para o recebimento de recursos dos projetos. \\
\hline 12 & Gerenciar recursos & $\begin{array}{l}\text { Realiza a gestão financeira dos projetos, com controles dos custos e } \\
\text { gastos. }\end{array}$ \\
\hline 13 & Contabilizar & Registra os fatos contábeis necessários as demonstrações contábeis \\
\hline 14 & Prestar contas & Exerce as atividades de finalização dos projetos com prestação de contas. \\
\hline 15 & Conciliar & $\begin{array}{l}\text { Realiza o controle interno das atividades financeiras por meio da } \\
\text { conciliação entre os registros contábeis e os extratos bancários }\end{array}$ \\
\hline
\end{tabular}

Quadro 1 Atividades realizadas na FAPEU

Fonte: Dados da pesquisa

Depois de listas e descritas as atividades, a terceira etapa consiste em identificar os

Rev. GUAL., Florianópolis, v. 4, n. 3, p.21-43, set/dez. 2011 
custos. Para isso foram levantados os valores gastos durante o mês de junho de 2010, tendo em vista que o convênio que será custeado foi executado durante este mesmo mês. Os gastos foram divididos em principais e secundários. Os principais são aqueles essenciais ao desenvolvimento do convênio e os secundários são aqueles consumidos pelas atividades secundárias. No Quadro 2 são apresentados estes valores, juntamente com os direcionadores de custos utilizados - etapa quatro.

\begin{tabular}{|l|c|l|}
\hline \multicolumn{1}{|c|}{ GASTOS } & R\$ & \multicolumn{1}{c|}{ DIRECIONADOR } \\
\hline Pessoal & 194.437 & Número de pagamentos realizados \\
\hline Despesas unidade & 206.393 & Número de compras efetuadas \\
\hline Condomínio & 18.809 & Metro quadrado \\
\hline $\begin{array}{l}\text { Gastos } \\
\text { secundários }\end{array}$ & 155.438 & Número de pedidos de material \\
\hline Total & $\mathbf{5 7 5 . 0 7 8}$ & \\
\hline
\end{tabular}

Quadro 2 Itens de custo e seus direcionadores

Fonte: Dados da pesquisa

Os valores dos gastos apresentados no Quadro 2 são compostos por:

- Pessoal: Estão englobados nesta conta os salários, encargos, $13^{\circ}$ salários, vale transporte, vale alimentação, seguros, provisão para rescisão e treinamento.

- Despesas unidade: Fazem parte das despesas gerais da unidade: telefone, material de consumo, reprografia, cartórios, correios, periódicos, transportes, eventuais passagens e hospedagens dos funcionários da fundação, cursos, etc..

- Condomínio: Gastos de uso comum: elevador, material de limpeza, cozinha, energia elétrica, água.

- Gastos das atividades secundárias: Gastos pertinentes as atividades do setor jurídico, recepção, direção, informática, arquivo e patrimônio. Por não fazerem parte do rol de atividades primordiais para a execução dos convênios, estas despesas são tratadas como secundárias.

Identificados os direcionadores, a quinta etapa consiste em alocar os custos as atividades. A sexta etapa, calcular o custo da atividade por hora, também será apresentada na Tabela 1, juntamente com a etapa anterior. 
Tabela 1 Alocação de custos e cálculo do CAH

\begin{tabular}{|c|c|c|c|c|c|c|c|}
\hline \multirow[b]{2}{*}{ ATIVIDADES } & \multicolumn{4}{|c|}{ ITENS DE CUSTO } & \multirow[b]{2}{*}{$\begin{array}{l}\text { Total } \\
\text { (CA) }\end{array}$} & \multirow{2}{*}{$\begin{array}{c}\text { Horas } \\
\text { trabalhadas } \\
(\mathrm{Np})\end{array}$} & \multirow[b]{2}{*}{$\begin{array}{c}\text { САН } \\
\mathrm{CA} \div \mathrm{Np}\end{array}$} \\
\hline & Pessoal & $\begin{array}{l}\text { Despesas } \\
\text { unidade }\end{array}$ & Condomínio & $\begin{array}{c}\text { Gastos } \\
\text { secundários }\end{array}$ & & & \\
\hline Comprar internamente & 23.711 & 10.508 & 2.674 & 29.734 & 66.627 & 128 & 520,52 \\
\hline Importar & 13.574 & 8.406 & 1.531 & 9.294 & 32.804 & 128 & 256,28 \\
\hline Efetuar reservas & 5.777 & 10.508 & 651 & 8.043 & 24.980 & 128 & 195,16 \\
\hline Licitar & 7.041 & 8.406 & 794 & 11.316 & 27.558 & 128 & 215,29 \\
\hline Apoiar CLT & 12.358 & 49.936 & 934 & 13.329 & 76.558 & 128 & 598,11 \\
\hline Apoiar bolsistas & 7.277 & 12.133 & 550 & 10.583 & 30.543 & 128 & 238,62 \\
\hline Apoiar prest.de serviço & 6.659 & 22.341 & 503 & 7.648 & 37.152 & 128 & 290,25 \\
\hline Gerenciar projetos & 17.723 & 10.508 & 2.215 & 12.495 & 42.941 & 128 & 335,48 \\
\hline Firmar contratos & 14.843 & 10.508 & 1.855 & 10.543 & 37.750 & 128 & 294,92 \\
\hline Pagar & 9.737 & 12.654 & 958 & 9.049 & 32.398 & 128 & 253,11 \\
\hline Receber & 9.536 & 12.654 & 938 & 5.628 & 28.756 & 128 & 224,66 \\
\hline Gerenciar recursos & 8.401 & 8.406 & 827 & 6.706 & 24.340 & 128 & 190,16 \\
\hline Contabilizar & 22.844 & 10.508 & 1.730 & 7.831 & 42.914 & 128 & 335,26 \\
\hline Prestar contas & 15.927 & 10.508 & 1.206 & 10.116 & 37.758 & 128 & 294,98 \\
\hline Conciliar & 19.028 & 8.406 & 1.441 & 3.121 & 31.997 & 128 & 249,98 \\
\hline TOTAL & 194.437 & 206.393 & 18.809 & 155.438 & 575.078 & 1.920 & $299,52 *$ \\
\hline
\end{tabular}

O custo da atividade por hora $(\mathrm{CAH})$ é obtido pela divisão do total dos custos de cada atividade pelo total de horas mensais trabalhadas naquela atividade, considerando-se para o cálculo apenas as horas efetivamente trabalhadas, por isso, o montante de 128 horas mensais. Cabe ressaltar que estas são as atividades que a FAPEU desenvolve na instituição como um todo. No caso deste trabalho, cujo objeto a ser custeado é o convênio Pequim Internacional 2, algumas das atividades listadas podem não ser necessárias para a execução deste projeto, mas como o objetivo é desenvolver um modelo que possa ser aplicado a outros convênios, apresentam-se todas as atividades da fundação.

Assim, a Tabela 2, além de apresentar o custo total do serviço base - etapa sete apresenta a contribuição de cada atividade para a formação deste valor. O custo do serviço base é obtido pela fórmula $\mathrm{CSB}=\Sigma(\mathrm{CAH}$ x Npa), onde $\mathrm{CAH}$ é o Custo da Atividade por Hora e o Npa o tempo de passagem do serviço padrão na atividade. Neste estudo, o convênio Pequim Internacional 2 é o próprio serviço base. 
Tabela 2 Custo do Serviço Base

\begin{tabular}{l|c|c|c}
\multicolumn{1}{c|}{ ATIVIDADES } & CAH & NPA & $\begin{array}{c}\text { CSB } \\
\text { (CAH x NPA) }\end{array}$ \\
\hline Comprar internamente & 520,52 & 1,63 & 848,44 \\
\hline Importar & 256,28 & - & - \\
\hline Efetuar reservas & 195,16 & - & - \\
\hline Licitar & 215,29 & - & - \\
\hline Apoiar CLT & 598,11 & - & 145,55 \\
\hline Apoiar bolsistas & 238,62 & 0,61 & 983,94 \\
\hline Apoiar prestadores de serviço & 290,25 & 3,39 & - \\
\hline Gerenciar projetos & 335,48 & - & $2.516,65$ \\
\hline Firmar contratos & 294,92 & 8,53 & 323,98 \\
\hline Pagar & 253,11 & 1,28 & 687,45 \\
\hline Receber & 224,66 & 3,06 & $1.622,69$ \\
\hline Gerenciar recursos & 190,16 & 8,53 & 36,87 \\
\hline Contabilizar & 335,26 & 0,11 & $1.510,29$ \\
\hline Prestar contas & 294,98 & 5,12 & $4.654,62$ \\
\hline Conciliar & 249,98 & 18,62 & $\mathbf{1 3 . 3 3 0 , 5 5}$ \\
\hline TOTAL DO SERVIÇO BASE & & & \\
\hline
\end{tabular}

Fonte: Dados da pesquisa

A Tabela 2 apresenta o custo do serviço base, ou seja, o quanto a fundação gastou para a execução do convênio em questão. Conforme se observa na Tabela, não foi necessária a utilização de todas as atividades executadas pela fundação neste convênio. Percebe-se ainda, que o custo total que a mesma arcou com a execução deste projeto foi de $\mathrm{R} \$ 13.330,55$, portanto, no mínimo este valor deve ser ressarcido a título de despesas administrativas.

Ao efetuar um comparativo com a Portaria Interministerial $n^{\circ} 127$ de 29 de maio de 2008, cuja redação diz que as despesas podem ser reembolsadas desde que não ultrapassem quinze por cento do objeto do contrato, verifica-se que a fundação opera dentro deste limite, pois, o valor do convênio é de $\mathrm{R} \$ 250.000,00$ e quinze por cento deste valor representa $\mathrm{R} \$$ $37.500,00$.

No caso deste estudo, o serviço base coincide com o objeto a ser custeado. No entanto, se o objetivo do trabalho fosse custear todos os projetos da fundação, e utilizando a lógica da UEP, todos os demais convênios seriam custeados com base no Pequim Internacional 2. Isto porque, os valores dos custos podem sofrer alterações, mas, as relações de esforços empregados entre as atividades se mantêm constantes.

Em consonância com a lógica do serviço base, Silva (2006, p.39) diz que a "UEP busca a criação de uma unidade de medida capaz de permitir uma homogeneidade entre os 


\section{ESTRUTURAÇÃO DE UM MODELO DE CUSTEIO HÍBRIDO PARA UMA FUNDAÇÃO DE APOIO UNIVERSITÁRIA}

produtos ou serviços produzidos, por meio da comparação da proporção de esforços produtivos que cada um destes itens consome durante seu processo de realização, em relação a um serviço utilizado como matriz".

Para Martins (2003, p. 312), "o método das Unidades de Esforço de Produção (UEP) consiste na construção e utilização de uma unidade de medida dos esforços e recursos aplicados na produção de vários produtos". Ou seja, o custo do produto base é a medida que serve de parâmetro para os demais serviços prestados pela fundação.

A oitava etapa é justamente o cálculo da constante de esforço da atividade (CEA), que é utilizada para atribuir os custos aos demais convênios e contratos celebrados pela fundação. A Tabela 3 apresenta os cálculos:

Tabela 3 Cálculo da CEA

\begin{tabular}{l|c|c|c}
\hline \multicolumn{1}{c|}{ ATIVIDADES } & CAH & CSB & $\begin{array}{c}\text { CEA } \\
\text { (CAH } \div \\
\text { CSB })^{*} 100\end{array}$ \\
\hline Comprar internamente & 520,52 & $13.330,55$ & 3,90 \\
\hline Importar & 256,28 & $13.330,55$ & 1,92 \\
\hline Efetuar reservas & 195,16 & $13.330,55$ & 1,46 \\
\hline Licitar & 215,29 & $13.330,55$ & 1,62 \\
\hline Apoiar CLT & 598,11 & $13.330,55$ & 4,49 \\
\hline Apoiar bolsistas & 238,62 & $13.330,55$ & 1,79 \\
\hline Apoiar prestadores de serviço & 290,25 & $13.330,55$ & 2,18 \\
\hline Gerenciar projetos & 335,48 & $13.330,55$ & 2,52 \\
\hline Firmar contratos & 294,92 & $13.330,55$ & 2,21 \\
\hline Pagar & 253,11 & $13.330,55$ & 1,90 \\
\hline Receber & 224,66 & $13.330,55$ & 1,69 \\
\hline Gerenciar recursos & 190,16 & $13.330,55$ & 1,43 \\
\hline Contabilizar & 335,26 & $13.330,55$ & 2,51 \\
\hline Prestar contas & 294,98 & $13.330,55$ & 2,21 \\
\hline Conciliar & 249,98 & $13.330,55$ & 1,88 \\
\hline
\end{tabular}

Após o cálculo da constante de esforço de produção multiplicou-se os valores obtidos por cem para facilitar as análises e minimizar os efeitos dos arredondamentos. A CEA estabelece uma relação constante entre o custo da hora de cada atividade executada pela FAPEU e o custo do serviço base $(\mathrm{CEA}=\mathrm{CAH} \div \mathrm{CSB})$. Ao utilizar as compras nacionais como exemplo, pode-se dizer que uma hora desta atividade corresponde a 3,9\% do custo total do serviço base. Assim, desde que não ocorram mudanças significativas nas atividades desenvolvidas pela fundação em estudo esta relação se manterá constante, o que facilita o 
cálculo do custo dos demais convênios/projetos (inclusive nos meses seguintes) executados pela fundação.

Diante dos cálculos apresentados, a metodologia de custeio híbrida se mostrou como um instrumento que fornece as informações pretendidas pela fundação, ou seja, o quanto ela gasta para executar um determinado convênio. No caso deste trabalho, optou-se por estruturar um modelo para as fundações de apoio, custeando o convênio Pequim Internacional 2 para verificar a aplicabilidade do modelo desenvolvido. No entanto, com a CEA calculada, os demais convênios e projetos também podem ser custeados sem maiores restrições.

\section{CONCLUSÕES}

A realização deste estudo se deve à necessidade de informações contábeis referentes aos custos dos serviços prestados pelas fundações, tendo em vista a necessidade destas informações para ressarcimento das despesas. De acordo com Iudícibus (2004), verifica-se que um sistema simples de registro e análise de dados deve estar presente na mais rudimentar das organizações. Desta forma, acredita-se na relevância do desenvolvimento deste trabalho para a fundação objeto deste estudo, bem como para as demais fundações que possam se interessar pelo modelo.

Assim, o objetivo deste trabalho é estruturar um modelo de custeio híbrido - baseado na união dos conceitos do Custeio Baseado em Atividades (ABC) e do Método das Unidades de Esforço de Produção (UEP) - que possibilite quantificar os gastos necessários para a realização de projetos de pesquisa de fundações de apoio. Para atingir este objetivo e criar um modelo para as fundações, utiliza-se como objeto de estudo o convênio Pequim Internacional 2, desenvolvido pela Fundação de Amparo a Pesquisa e Extensão Universitária.

Utiliza-se uma metodologia de custeio híbrida, pois se acredita que com isso as deficiências do ABC e da UEP sejam supridas. Além do mais, com a junção destes métodos ocorre a possibilidade de maximizar os pontos fortes, ou seja, o detalhamento da informação fornecida pelo $\mathrm{ABC}$ com a simplicidade de operacionalização da UEP.

Este estudo está baseado em duas correntes distintas: uma teórica e outra prática. I) A primeira busca trazer contribuições para o meio acadêmico nos aspectos que tangem a metodologia de custeio híbrida aplicada à prestação de serviço, em especial, as fundações. II) A segunda, ao levar em consideração a necessidade teórica já mencionada, optou-se por unir a 
teoria e a prática, tendo em vista a necessidade que as fundações possuem em quantificar seus gastos para ressarcimento futuro.

O convênio Pequim Internacional 2 foi realizado no mês de junho de 2010 e os gastos apresentados durante o trabalho são referentes a este mesmo período. Para estruturar o modelo, primeiramente mapeou-se o fluxo dos processos da FAPEU, na sequência identificaram-se as atividades principais, seus direcionadores de custos e seus custos mensais.

Depois de estruturado o modelo e aplicado ao convênio Pequim Internacional 2, conclui-se que tal convênio acarretou em R\$ 13.330,55 de custos para a fundação, portanto, no mínimo este valor deve ser reembolsado. Em relação ao total do objeto conveniado a fundação ainda está operando dentro do limite de quinze por cento estipulados pela Portaria Interministerial $\mathrm{n}^{\mathrm{o}} 127$ de 29 de maio de 2008.

No geral, pode-se afirmar que a metodologia aplicada atingiu seu objetivo e pode ser adotada pela fundação para custear os demais convênios, que estão ativos, ou que ainda virão a acontecer. Além do objetivo principal, desenvolver um modelo de custeio para as fundações, esta metodologia se apresenta como uma importante ferramenta de gestão para a fundação, pois, pode-se verificar onde estão as maiores concentrações de custos, quais as atividades poderiam ser eliminadas do processo, entre outras. Esta verificação é possível graças à sistemática adotada, no qual foram mapeadas as atividades principais da fundação, o que resulta em uma possível verificação de onde estão às deficiências da organização.

Acredita-se que o modelo estruturado para a FAPEU possa ser utilizado pelas demais fundações de apoio, desde que, efetuadas as adaptações necessárias, tendo em vista as peculiaridades de cada instituição. Para comprovar esta idéia, sugere-se para futuros trabalhos a aplicação desta metodologia em outras fundações de apoio, inclusive vinculadas a outras IFES, para confrontação dos resultados obtidos.

\section{REFERÊNCIAS}

BEUREN, Ilse Maria; SCHLINDWEIN, Nair Fernandes. Uso do Custeio por Absorção e do Sistema RKW para gerar informações gerenciais: um estudo de caso em hospital. In:

Abcustos. Associação brasileira de custos. Vol. III n 2 - mai/ago 2008.

BORGERT, Altair.; BORBA, José. A.; SILVA, Márcia. Z. Um método de custeio híbrido para mensuração dos custos em uma empresa prestadora de serviço por encomenda. In: XXV ENEGEP (2005, Porto Alegre, RS, Brasil). Anais... Porto Alegre: ABEPRO, 2005.

Rev. GUAL., Florianópolis, v. 4, n. 3, p.21-43, set/dez. 2011 
BORNIA, Antonio Cezar. Análise gerencial de custos: aplicação em empresas modernas. Porto Alegre: Bookman, 2002.

BRASIL. Lei $\mathbf{n}^{\mathbf{0}} \mathbf{8 . 9 5 8}$, de 20 de dezembro de 1994. Dispõe sobre as relações entre as instituições federais de ensino superior e de pesquisa científica e tecnológica e as fundações de apoio e dá outras providências. Disponível em:

$<$ http://www.planalto.gov.br/ccivil_03/Leis/L8958.htm>, Acesso em: 20 de janeiro de 2011.

BRASIL. Instrução Normativa STN nº 01, de 15 de janeiro de 1997. Disciplina a celebração de convênios de natureza financeira que tenham por objeto a execução de projetos ou realização de eventos e dá outras providências. Disponível em:

$<$ http://www.tesouro.fazenda.gov.br/legislacao/download/contabilidade/IN1_97.pdf $>$, Acesso em: 19 de novembro de 2010.

BRASIL. Portaria Interministerial $\mathrm{n}^{\mathbf{0}} 127$ de 29 de maio de 2008. Estabelece normas para execução do disposto no Decreto $n^{\circ} 6.170$, de 25 de julho de 2007, que dispõe sobre as normas relativas às transferências de recursos da União mediante convênios e contratos de repasse, e dá outras providências. Disponível em:

$<$ http://www.conveniosfederais.com.br/Portarias/InterMin127_08_busca_nova.html $>$, Acesso em: 15 de novembro de 2010.

DINIZ, Maria Helena. Direito fundacional. São Paulo: Oliveira Mendes, 1998.

ERHART, A.; NETTO, F. P.; OTTONI, F. L.; GOULART, R. N. Avaliação e aprimoramento de sistemas de custeio: o caso de uma empresa de borrachas. In: ENEGEP - Encontro

Nacional de Engenharia de Produção, 2005, Porto Alegre. Anais do XXVI ENEGEP. Rio de Janeiro: ABEPRO, 2005.

FUNDAÇÃO DE EMPREENDIMENTOS CIENTÍFICOS E TECNOLÓGICOS - FINATEC. Institucional. O que são fundações de Apoio? Disponível em:

$<\mathrm{http}$ //www.finatec.org.br/site/index.php?option=com_content\&view=article\&id=51\&Itemid $=109>$, Acesso em: 23 de janeiro de 2010 .

FUNDAÇÃO DE AMPARO À PESQUISA E EXTENSÃO UNIVERSITÁRIA - FAPEU. Institucional. Apresenta informações referentes à fundação. Disponível em: $<$ http://www.fapeu.org.br/hpverde/fapeu.html $>$. Acesso em: 18 de novembro de 2010.

HANSEN, Don R; MOWEN, Maryanne M. Gestão de custos: contabilidade e controle. São Paulo: Pioneira, 2001.

IUDICIBUS, Sergio de. Teoria da contabilidade. 7. ed. São Paulo: Atlas, 2004.

KLIEMANN NETO, Francisco José. Gerenciamento e controle da produção pelo método das unidades de esforço de produção. CONGRESSO BRASILEIRO DE GESTÃO ESTRATÉGICA DE CUSTOS, 1, 1995, São Leopoldo, Anais. Unisinos, 1995.

KRAEMER, Tânia Henke. Discussão de um sistema de custeio adaptado às exigências da 
nova competição global. 1995. 148 f. Dissertação (Mestrado em Engenharia de Produção)Universidade Federal do Rio Grande do Sul, Porto alegre, 1995.

LEONE, George Sebastião Guerra. Custos: planejamento, implantação e controle. 3. ed. São Paulo: Atlas, 2000.

MACHADO, Alessandra. O.; BORGERT, Altair.; LUNKES, Rogério. J. ABC e UEP - um ensaio em empresa de software. In: XIII Congresso Brasileiro de Custos (2006, Belo Horizonte, MG, Brasil). Anais... Belo Horizonte: ABC, 2006.

MARTINS, Eliseu. Contabilidade de custos. 9. ed. São Paulo: Atlas, 2006.

MARTINS, Sônia Sevilha; BARRELA, Wagner Däumichen. Composição do sistema de custeio: uma aplicação prática. In: ENCONTRO NACIONAL DE ENGENHARIA DE PRODUÇÃO, XXII, 2002, Curitiba. Disponível em:

$<$ http://www.abepro.org.br/biblioteca/ENEGEP2002_TR32_1098.pdf>. Acesso em: 25 maio de 2010 .

MINISTÉRIO DA EDUCAÇÃO - MEC. Fundações de apoio. Disponível em:

$<$ http://portal.mec.gov.br/index.php?Itemid=1022\&id=12508\&option=com_content\&view=ar ticle>, Acesso em: 12 de janeiro de 2011.

MIRANDA, Vera Lúcia Murta. Imunidades e isenções tributárias no âmbito do poder público: benefícios e beneficiários. In. Espírito Santo (Estado). Ministério Público. Procuradoria-Geral de Justiça. Centro de Estudos e Aperfeiçoamento Funcional. Terceiro Setor: Fundações e entidades de interesse social. Vitória: CEAF, 2004.

NAKAGAWA, Masayuki. ABC: custeio baseado em atividades. 2. ed. São Paulo: Atlas, 2001.

PAES, José Eduardo Sabo. Fundações, associações e entidades de interesse social: aspectos jurídicos, administrativos, contábeis, trabalhistas e tributários. 6.ed. rev., atual. e ampl. de acordo com o novo Código Civil Brasileiro. Brasília: Brasília Jurídica, 2006.

PASQUATTI, Norberto. O terceiro setor e os direitos sociais. In: PANTALEÃO, Leonardo (Org.). Fundações educacionais. São Paulo: Atlas, 2003.

SILVA, Márcia. Z. Mensuração dos custos de procedimentos médicos em organizações hospitalares: sistematização de um método de custeio híbrido à luz do $\mathrm{ABC}$ e da UEP. Dissertação (Mestrado em contabilidade), Programa de Pós-Graduação em Contabilidade, Universidade Federal de Santa Catarina, Florianópolis. 2006.

SILVA, Márcia Z.; BORGERT, Altair; SCHULTZ, Charles. Sistematização de um método de custeio híbrido para o custeamento de procedimentos médicos: uma aplicação conjunta das metodologias ABC e UEP. Revista de Ciências da Administração. v. 11, n. 23, p. 217-244, jan/abr 2009. 
SILVEIRA, Douglas da. Evidenciação contábil de fundações privadas de educação e pesquisa: uma análise da conformidade das demonstrações contábeis de entidades de Santa Catarina. 2007. 140 f. Dissertação (mestrado em contabilidade), Programa de Pós-Graduação em Contabilidade, Universidade Federal de Santa Catarina, Florianópolis, 2007.

VANDERBECK, Edward J.; NAGY, Charles F. Contabilidade de custos. 11. ed. São Paulo: Pioneira, 2001. 


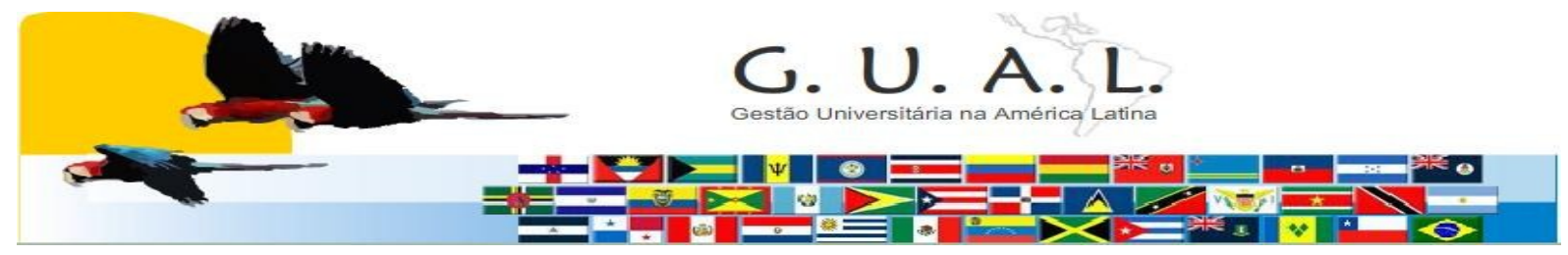

ISSN 1983-4535

\title{
STRUCTURE OF A HYBRID MODEL COSTING FOR A FOUNDATION TO SUPPORT UNIVERSITY
}

\author{
Fernando Richartz, Master \\ Universidade Federal de Santa Catarina - UFSC \\ nandorichartz@hotmail.com \\ Altair Borgert, Doctor \\ Universidade Federal de Santa Catarina - UFSC \\ borgert@cse.ufsc.br
}

Ráriton Silva, Bachelor

Fundação de Amparo a Pesquisa e Extensão Universitária da UFSC - FAPEU

rariton@fapeu.org.br

\begin{abstract}
The objective of this paper is to structure a hybrid cost model (UEP and ABC) to quantify the capital expenditure required in the management of research projects of a foundation to support university. As the object of study, we use the convention Pequim International 2, developed by the Fundação de Amparo a Pesquisa e Extensão Universitária. The data needed for the structuring of the model were collected through spot verification and with the managers of the foundation, in particular, the financial management, during the second half year of 2010. The model was structured through eight main stages based on the literature. Its application showed a cost of $\mathrm{R} \$ 13.330,55$ for the project in question. So at least this amount as compensation for administrative expenses. In relation to the total object insurance ( $\mathrm{R} \$ 250,000.00)$, the expenses of the foundation are still within the limit of fifteen percent ( $\mathrm{R} \$ 37,500.00)$ stipulated by Portaria Interministerial $\mathrm{n}^{\mathrm{o}} 127$ de 29 de maio de 2008, according to results the cost model hybrid. In addition to costing of agreements, this methodology is presented as an important management tool for the foundations to allow the mapping of activities in line with its measurement and its control, which allows management of the organization's points deficit.
\end{abstract}

Keywords: Hybrid cost model. ABC. UEP. Support foundation. 